\title{
Influence of Maternal Autonomy Support on Social Withdrawal in Young Children: The Moderated Mediation Effect of Executive Function and Behavioral Inhibition
}

\author{
Su Lim Kang ${ }^{1}$, Sunhee Kim² \\ M. A., Department of Child Development and Family Studies, Pusan National University, Busan, Korea ${ }^{1}$ \\ Professor, Department of Child Development and Family Studies, Pusan National University, Busan, Korea ${ }^{2}$ \\ 어머니의 자율성 지지가 유아의 사회적 위축에 미치는 영향: \\ 실행기능과 행동억제기질의 조절된 매개효과 \\ 강수림 ${ }^{1}$, 김선희 ${ }^{2}$ \\ 부산대학교 아동가족학과 석사 ${ }^{1}$, 부산대학교 아동가족학과 교수 ${ }^{2}$
}

Objectives: This study investigated the relationship between maternal autonomy support and social withdrawal, executive function, and behavioral inhibition in young children. Specifically, it examined how behavioral inhibition moderates the mediating effect of executive function on the relationship between maternal autonomy support and social withdrawal in young children.

Methods: Participants were 273 3-to 4-year-old children and their mothers. The data obtained were analyzed using descriptive statistics, frequency analysis, Cronbach's $\alpha$, and Pearson correlation analysis with SPSS 20.0. Meanwhile, the PROCESS Macro 3.5 software was used for analyzing the moderating effect, mediating effect, and moderated mediation effect.

Results: Our findings indicated that, first, maternal autonomy support and executive function, social withdrawal, and behavioral inhibition in young children were significantly correlated. Second, executive function had a partial mediating effect on the relationship between maternal autonomy support and social withdrawal in young children. Third, the behavioral inhibition had a moderating effect on the relationship between maternal autonomy support and executive function. Last, the findings verified that the mediating effect of executive function on the relationship between maternal autonomy support and social withdrawal was moderated by behavioral inhibition.

Conclusion: These results indicate that improving executive function and reducing social withdrawal through maternal autonomy support can promote positive development in young children, even when behavioral inhibition is high. Thus, they can be used to highlight the importance of parenting behaviors in shaping young children's temperament. Furthermore, the results could provide a framework for parental education programs and early intervention programs for reducing social withdrawal in children.

Keywords: young children, social withdrawal, executive function, behavioral inhibition, maternal autonomy support

Corresponding Author: Sunhee Kim, Professor, Department of Child Development and Family Studies, Pusan National University, 2, Busandaehak-ro 63beon-gil, Geumjeong-gu, Busan, Korea

E-mail: kremedy@pusan.ac.kr
(c)The Korean Association of Child Studies

This is an Open Access article distributed under the terms of the Creative Commons Attribution Non-Commercial License (http:// creativecommons.org/licenses/by-nc/4.0) which permits unrestricted noncommercial use, distribution, and reproduction in any medium, provided the original work is properly cited. 


\section{Introduction}

유아기의 중요한 발달과제 중 하나는 또래와 긍정적인 관계 를 맺고 유지하는 것이다(Coplan \& Ooi, 2014). 이는 이전 시 기와 달리 가정에서 벗어나 유아교육기관에서 다른 유아나 집 단과의 상호작용이 더욱 빈번해지고 다양해지기 때문이다(W.

$\mathrm{Kim}, \mathrm{Kim}, \mathrm{Lee}, \& \mathrm{Nam}, 2014)$. 그러나 또래와 성공적인 관계 를 맺는 유아가 있는 반면, 또래와의 놀이에 참여하지 못하고 위축된 행동을 보이는 유아들도 있다(Jo \& Shin, 2017).

사회적 위축은 또래와 상호작용을 하지 못하거나 불안이 나 두려움으로 인해 소극적이고 회피적인 태도를 보이는 것을 의미한다(Coplan, Ooi, Xiao, \& Rose-Krasnor, 2018; Gazelle \& Ladd, 2003). Coplan 등(2018)은 사회적 위축이 타인에게 접근 하고자 하는 접근 동기와 타인과의 상호작용을 회피하려는 회 피 동기 두 가지 상반된 동기의 내적 갈등에 따라 갈등적 수줍 음, 사회적 무관심, 사회적 회피로 구분된다고 하였다. 갈등적 수줍음은 접근 동기와 회피 동기가 모두 높은 반면, 사회적 무 관심은 접근 동기와 회피 동기가 모두 높아 사회적 상호작용 을 어려워하는 것을 의미하며, 사회적 회피는 접근 동기는 낮 으나 회피 동기가 높아 사회적 상호작용을 피하는 것을 의미 한다(Coplan et al., 2018). 또래와의 상호작용은 사회적 기술을 획득하고 타인에 대한 조망수용능력을 배우도록 도와주는 역 할을 한다. 그러나 위축된 유아는 이러한 기회를 놓치게 되어 타인과의 관계 형성이나 사회성 발달에 어려움을 겪게 된다 (Rubin, Coplan, \& Bowker, 2009). 특히, 유아기에 나타나는 사 회적 위축 행동은 청소년기까지 지속적으로 유지되는 경향이 있는데, Rubin과 Wilkinson (1990)의 연구에서 유아기의 사회 적 위축은 청소년기의 외로움, 우울을 유의하게 예측하였다. 또한 사회적 위축은 우울, 불안과 같은 내재화 문제행동뿐만 아니라 공격성 등의 외현화 문제행동과도 밀접한 관련이 있는 것으로 나타났다(Coplan et al., 2018). 이를 통해 유아의 사회 적 위축은 개인의 삶에 장단기적인 영향을 미침을 알 수 있다. 따라서 유아의 사회적 위축에 영향을 미치는 요인들을 탐색하 고, 서로 어떠한 관련성을 보이는지 살펴볼 필요가 있다.

유아의 사회적 위축에 영향을 미치는 요인으로 크게 환경 적 요인과 개인적 요인이 있다. 우선 환경적 요인으로는 부모 의 양육행동(Zarra-Nezhad et al., 2014), 교사와의 관계(Jo \& Shin, 2017) 등이 있다. 개인적 요인으로는 유아의 기질(Kiel \& Buss, 2014), 정서조절능력(J. A. Han, 2016), 실행기능(Toren et al., 2000) 등이 있다. 그러나 유아의 사회적 위축은 환경적 요 인과 개인적 요인이 서로 상호작용하여 발생하므로(Younger
\& Daniels, 1992), 각 요인들이 서로 어떠한 영향을 미치고, 어 떠한 경로를 통해 발생하는지를 살펴볼 필요가 있다.

유아는 어머니와의 상호작용 경험을 바탕으로 또래와의 관 계를 형성하게 된다(S.-R. Kim, 2020). 따라서 유아의 사회적 위축에 영향을 미치는 환경적 요인 중, 유아의 첫 사회화 대행 자인 어머니의 양육행동을 고려해 볼 필요가 있다. 특히, 위축 된 유아의 경우, 어머니가 유아의 관점과 결정을 지지해 주고, 주도적으로 문제를 해결할 수 있도록 격려하며 선택권을 제공 하는 자율성 지지가 중요하다(Grolnick, Gurland, DeCourcey, $\&$ Jacob, 2002; Joussemet, Koestner, Lekes, \& Landry, 2005). 자 기결정성 이론에 따르면(Deci \& Ryan, 1985), 자율성은 인간 의 기본적인 심리 욕구로, 이를 충족시키기 위해서는 유아의 행동을 통제하기보다 자율성을 촉진시키는 양육행동이 중요 하다고 하였다. 특히 이러한 양육행동은 주도성을 발달시켜 나가는 유아기에 스스로 유능감을 느낄 수 있도록 한다는 측 면에서 강조된다. 이와 관련하여 선행연구들은 어머니가 유아 의 자율성을 인정해주는 경우, 사회적으로 위축되지 않고 성 공적인 또래관계를 맺는 것으로 나타났다(H. G. Hong, 2015; Moon \& Shin, 2017). 반면 어머니가 유아의 행동을 통제하고 지나치게 관여하는 경우, 유아의 사회적 위축이 증가하는 것 으로 나타났다(Kiel \& Buss, 2014). Park (2013)의 연구에서도 어머니가 독립심을 많이 격려할수록 걸음마기 아동은 더 낮은 수준의 사회적 위축을 보였다. 이를 통해 어머니가 유아의 주 도성을 지지해 주면 유아가 사회적 상황에서 타인에게 의존하 기보다 스스로 대처할 수 있는 능력이 발달하여 자신감 있게 행동할 가능성이 높음을 알 수 있다. 따라서 본 연구에서는 어 머니의 자율성 지지가 높을수록 유아의 사회적 위축이 감소할 것으로 가정하고 이러한 과정에서 유아의 개인적 요인인 실행 기능이 어떠한 영향을 미치는지 살펴보고자 한다.

유아의 사회적 위축에 영향을 미치는 개인 내적 요인 중 하 나인 실행기능은 목표를 달성하기 위해 계획을 세우며, 자신 의 정서, 사고, 행동을 억제하는 고차원적인 인지능력으로, 억제, 작업기억, 전환, 감정조절, 계획 및 조직화로 구성된다 (Gioia, Isquith, Guy, \& Kenworhy, 2000; Welsh, Pennington, \& Grosser, 1991). 실행기능은 만 3세를 기점으로 급격하게 발달 하는데, 사회, 정서, 적응을 비롯한 또래관계를 예측한다는 점 에서 발달적 중요성이 있다(Chevalier \& Clark, 2017). 실행기 능이 낮은 유아는 높은 수준의 불안과 좌절감을 보이는데, 불 안이 높은 유아의 경우, 사고가 경직되어 효율적으로 정보를 처리하기 어렵고 사회적 관계를 회피한다(Toren et al., 2000). 또한 자신의 행동에 대한 계획을 세우기 어렵고, 사회적 상황 
에서 자신의 정서와 사고를 조절하지 못하여 또래관계에서 위 축된다(Kiel \& Buss, 2011; Liew, 2012). 국내연구에서도 실행 기능이 높은 유아는 문제해결능력이 높아 갈등상황에서 유연 한 태도로 반응하고 적절하게 대처함으로써 위축된 행동을 덜 보이는 것으로 나타났다(S.-R. Kim, 2020). 즉, 유아의 실행기 능 수준은 유아가 사회적 관계 속에서 어떠한 행동양식을 사 용해야할지 결정하는데 영향을 미친다. 한편 실행기능은 환경 적인 요인에 의해 변화 가능하며(Bernier, Carlson, Deschênes, \& Matte-Gagné, 2012), 그중에서도 어머니 양육행동은 중요 한 요소로 작용한다(Chevalier \& Clark, 2017). 특히 유아기는 이전과 달리 더 넓은 환경에서 많은 도전을 받게 되는데, 도전 에 성공적으로 대처하기 위해서는 유아가 스스로 계획을 세우 고 행동하는 것이 중요하다(Cha, 2018). 이때, 어머니가 유아 의 관점과 결정을 지지해 주면 유아는 목표를 설정하고 성취 할 수 있으며, 자신의 행동을 스스로 조절할 수 있다(Joussemet et al., 2005). 따라서 선행연구를 종합해보면 어머니의 자율성 지지는 실행기능을 향상시키고(Bernier et al., 2012; Chevalier \& Clark, 2017), 실행기능은 사회적 위축 감소에 영향을 미침 (Liew, 2012)을 알 수 있다.

한편 어머니의 자율성 지지는 유아의 실행기능의 개인차 를 예측하는 중요한 요인이지만, 이러한 영향은 유아의 기질 에 따라 달라질 수 있다. 특히 행동억제기질은 친숙하지 않 은 상황이나 사람, 새로운 감각자극에 대해 두려움과 경계심 을 보이는 기질적 특성이다(Pérez-Edgar et al., 2011). 또한 낮 설거나 도전적인 상황에서 불안하거나 힘들어하는 반응 양 식이나 행동을 의미하며, 유아의 인지발달을 저해한다(Thai, Taber-Thomas, \& Pérez-Edgar, 2016). 이는 우측 전두엽의 활성 화와 코르티솔 분비와 같은 생물학적 기저와 관련이 있다(Fox, Henderson, Marshall, Nichols, \& Ghera, 2005). 행동억제기질 수 준이 높은 유아는 코르티솔 분비량이 많은 경향이 있는데, 많 은 양의 코르티솔은 전두엽의 두께를 감소시켜 작업기억이나 전환과 같은 실행기능을 저하시킨다(Feola, Dougherty, Riggins, $\&$ Bolger, 2020). 또한 Gramszlo 등(2018)의 연구에 따르면, 행 동억제기질 수준이 높을수록 두려움과 공포에 주의가 편향되 어 주의를 전환하는 능력이 감소되는 반면, 행동억제기질 수 준이 낮을수록 다른 자극을 통제하고 주의를 집중하는 능력이 증가한다(Buss \& Kiel, 2013). 이와 같이 유아의 행동억제기질 수준이 높을수록 실행기능에 부정적인 영향을 미침을 알 수 있다.

그러나 어머니가 유아의 자율성을 지지해 주면 행동억제기 질 수준이 높은 유아라 하더라도 실행기능이 증진될 수 있다.
유아가 낮선 환경을 두려워하더라도 어머니가 유아의 행동 을 지지해 줌으로써 유아가 독립적으로 환경을 탐색할 수 있 을 것이며(Rochette \& Bernier, 2016), 이를 통해 도전의 기회가 많아지면 문제해결능력이 향상되어 실행기능이 발달할 것으 로 예측해 볼 수 있다. 또한 선행연구에서 두려움을 많이 느끼 는 기질의 유아는 어머니가 유아의 행동과 정서를 지지해 주 고 긍정적인 관계를 맺을수록 실행기능이 더욱 증가하였다고 밝혔다(Rochette \& Bernier, 2016; Suor, Sturge-Apple, Davies, \& Jones-Gordils, 2019). 이는 행동억제기질 수준이 높은 경우, 상 호작용의 질이 높고 애정적인 양육행동을 보이거나 유아의 자 율성을 지지해 주는 양육행동을 보일 때 모두에서 더 긍정적 인 발달을 보이는 것으로 미루어보면(M.-K. Kim, 2011; Y. H. Seo, 2013), 어머니의 자율성 지지와 유아의 실행기능 간의 관 계에서 행동억제기질의 조절효과를 가정할 수 있다. 그러나 이에 대한 연구는 제한적이며, 긍정적인 양육행동(S.-R. Kim, 2020)과 같이 포괄적으로 검증하여 양육행동을 구체적으로 살펴 볼 필요가 있다.

이러한 개인차는 환경적 영향에 대한 민감성의 차이를 보 이기 때문인데, 이는 차별적 민감성 가설을 통해 설명될 수 있 다. 차별적 민감성 가설은 기질적 특성을 취약성이 아닌 민감 성의 관점에서 접근하는 것으로, 스트레스에 취약한 유아가 긍정적인 양육을 경험하면 더 높은 발달적 성취를 보이는 것 을 의미한다(Belsky, 1997). 그러나 차별적 민감성 가설을 지지 하는 대부분의 선행연구들은 까다로운 기질과 같이 포괄적인 기질 특성에 초점을 맞추고 있어 보다 구체적인 기질 특성에 대한 연구가 부족한 실정이다. 이에 어머니의 긍정적 양육행 동이 유아의 실행기능을 증진시킬 것으로 예상되는 유아의 기 질적 특성을 보다 구체화하여 살펴볼 필요가 있다.

종합하면, 행동억제기질 수준이 높은 유아라 하더라도 어 머니가 유아의 자율성을 지지해 주면 유아가 스스로 문제를 해결하고 목표 달성을 위해 자신의 행동과 사고를 조절하는 경험을 통해 실행기능이 향상됨을 유추해볼 수 있다. 이는 궁 극적으로 유아가 또래관계에서 자신의 충동성을 억제하고 긍 정적인 사고로의 빠른 전환을 통해 사회적으로 위축되지 않고 또래와 성공적인 관계를 맺을 수 있을 것이다.

따라서 본 연구에서는 어머니의 자율성 지지와 유아의 사 회적 위축 간의 관계에서 실행기능의 매개효과와 행동억제기 질의 조절효과를 확인하고, 이러한 관계를 통합한 조절된 매 개효과를 순차적으로 검증하고자 한다. 조절된 매개효과는 사 회적 위축에 대한 매개 및 조절 효과만을 검증한 선행연구와 는 달리 매개효과와 조절효과를 단일모형에 결합하여 보다 통 
합적으로 검증할 수 있으며, 매개변인을 거치는 인과적 경로 가 조절변인에 의해 어떻게 달라지는지 파악할 수 있어 정교 한 분석이 가능하다는 점에서 의의가 있다(Jung \& Seo, 2016).

본 연구의 목적은 어머니의 자율성 지지라는 환경이 유아 의 인지적 특성인 실행기능에 영향을 미쳐 사회적 위축으로 이어지는 인과적 경로가 행동억제기질에 의해 어떻게 달라지 는가를 검증하는 것이다. 이는 사회적 위축의 개인차를 설명 하는 심리적 과정을 보다 더 깊이 있게 이해하도록 돕는다. 나 아가 사회적 위축을 예방하고 조기에 중재할 수 있는 방안을 제공할 수 있을 것이다. 연구문제는 다음과 같다(Figure 1).

\section{연구문제 1}

유아의 실행기능은 어머니의 자율성 지지와 유아의 사회적 위축에 미치는 영향을 매개하는가?

\section{연구문제 2}

유아의 행동억제기질은 어머니의 자율성 지지가 유아의 실행 기능에 미치는 영향을 조절하는가?

\section{연구문제 3}

어머니의 자율성 지지, 유아의 실행기능, 사회적 위축의 관계 에서 행동억제기질의 조절된 매개효과가 나타나는가?

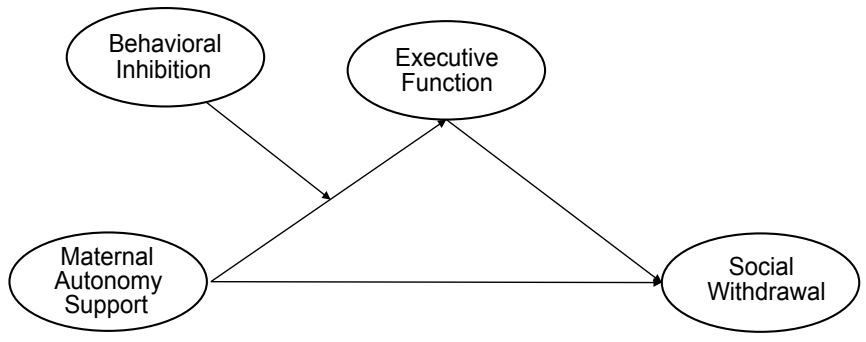

Figure 1. Study model.

\section{Methods}

\section{연구대상}

연구의 대상은 $\mathrm{B}$ 시와 $\mathrm{G}$ 도에 소재한 13 곳의 어린이집에 재원 하고 있는 만 3, 4세 유아 273명과 그들의 어머니이다. 유아 의 연령은 만 3 세 130 명(47.6\%), 만 4세 143 명(52.4\%)이었으 며, 성별은 남아 146 명(53.5\%)과 여아 127 명(46.5\%)으로 구 성되었다. 어머니의 연령은 30 세 이하가 10 명(3.7\%), 31-35
세가 64명(22.4\%), 35-40세가 130명(47.6\%), 40-45세가 65명 (23.89\%), 45세 이상은 4명(1.5\%)이었다. 교육수준은 대학교 졸업이 155 명(56.8\%)으로 가장 많았으며, 전문대 졸업 또는 대학교 중퇴가 67명(24.5\%), 대학원 이상이 26명(9.5\%), 고등 학교 졸업이 22명(8.1\%), 중학교 졸업이 3명(1.1\%)이었다. 월 가구소득은 200 만 원 이하가 2명(0.7\%), 201-300만 원이 22 명(8.1\%), 301-400만 원이 44명(16.1\%), 401-500만 원이 83명 (30.4\%), 501만 원 이상이 122 명(44.7\%)이었다. 30 명의 담당 보육교사의 경력은 1 년 미만이 1 명(3.3\%), 1 년 이상 3 년 미만 이 3명(10.0\%), 3-5년이 6명(20.0\%), 5-7년이 9명(30.0\%), 7-9 년이 4명(13.3\%), 9년 이상이 7명(23.3\%)이었다.

\section{연구도구}

$$
\text { 어머니의 자율성 지지 }
$$

어머니의 자율성 지지는 Grolnick, Ryan과 Deci (1991)의 부모 지각 척도(Perceptions of Parents Sclaes [POPS]), Williams와 Deci (1996)의 학습풍토 질문지척도(Learning Climate Questionnarie [LCQ]), Soenens 등(2007)의 자율성 지지 척도를 Noh, Park과 Chee (2011)가 수정, 보완한 척도를 사용하였다. 본 척도는 총 12 문항 단일요인으로 유아의 어머니가 평정하며, 문항의 예 로 "아이가 해야 할 일을 스스로 결정할 수 있게 해준다." 등이 있다. 각 문항은 매우 그렇지 않다(1점)부터 매우 그렇다(4점) 로 측정되고, 점수가 높을수록 어머니의 자율성 지지가 높음 을 의미한다. Noh, Park과 Chee (2011)의 연구에서 신뢰도 계 수(Cronbach's $\alpha$ )는 .77이었고, 본 연구에서는 .91로 나타났다.

\section{유아의 실행기능}

유아의 실행기능은 Gioia 등(2000)가 개발한 아동용 실행기 능척도를 기초로 유아용으로 타당화한 Isquith 등(2004)의 유아용 실행기능척도(Behavior Rating Inventory of Executive Function-Preschool version [BRIEF-P])를 J. Seo와 Park (2011)이 번안한 척도를 사용하였다. 본 척도는 총 63 문항으로 유아의 어머니가 평정하며, 문항의 예로 "문제 해결을 위한 어려운 과 제를 수행할 때 대안을 생각해내는 것을 어려워한다.” 등이 있 다. 하위요인으로는 억제(16문항), 작업기억(17문항), 전환(10 문항), 감정조절(10문항), 계획조직(10문항) 5 가지로 구성되 어 있다. 각 문항은 전혀 그렇지 않다(1점)부터 그렇다(4점)로 측정되고, 점수가 높을수록 실행기능이 낮음을 의미한다. 따 
라서 본 연구에서는 모든 문항을 역채점하였다. 본 연구의 전 체 신뢰도 계수(Cronbach's $\alpha$ )는 .98로 나타났다. J. Seo와 Park (2011)의 연구에서 하위요인별 신뢰도 계수는 억제 .97, 작업 기억 .97, 전환 .92, 감정조절 .94, 계획조직 .93이었고, 본 연구 에서는 $.94, .95, .90, .88, .89$ 으로 나타났다.

\section{행동억제기질}

유아의 행동억제기질은 Bishop, Spence와 McDonald (2003) 가 개발한 행동억제척도(Behavioral Inhibition Questionnarie [BIQ])를 Lee (2020)가 번안한 척도를 사용하였다. 본 척도는 총 30 문항으로 유아의 어머니가 평정하며, 문항의 예로 "새로 운 상황이나 활동에 매우 주저하며 다가간다.” 등이 있다. 하 위요인으로는 또래(6문항), 성인(4문항), 수행 상황(4문항), 분 리/유치원(4문항), 낮선 상황(8문항), 신체적 도전(4문항) 6가 지로 구성되어 있다. 각 문항은 거의 그렇지 않다(1점)부터 거 의 항상 그렇다(7점)로 측정되고, 점수가 높을수록 유아의 행 동억제기질이 높음을 의미한다. Lee (2020)의 연구에서 신뢰 도 계수(Cronbach's $\alpha$ )는 .94이었고, 본 연구에서는 .94로 나타 났다. 하위요인별 신뢰도 계수(Cronbach's $\alpha$ )는 또래 .82, 성인 .80 , 수행 상황 .75 , 분리/유치원 .79 , 낮선 상황 .83 , 신체적 도 전 .74로 나타났다.

\section{사회적 위축}

사회적 위축은 Coplan 등(2018)가 개발한 사회적 선호 척도 (Child Social Preference Scale-3 [CSPS-3])를 Ko (2019)가 교사평 정으로 수정, 번안한 척도를 사용하였다. 본 척도는 총 15 문항 으로 유아의 담임교사가 평정하며, 문항의 예로 "아이는 종종 다른 친구들과 놀지 않기 위해 자리를 피한다.” 등이 있다. 하위 요인으로는 갈등적 수줍음(7문항), 사회적 무관심(4문항), 사회 적 회피(4문항) 3 가지로 구성되어 있다. 각 문항은 전혀 그렇지 않다(1점)부터 매우 그렇다(5점)로 측정되고, 점수가 높을수록 사회적 위축이 높음을 의미한다. Ko (2019)의 연구에서 신뢰도 계수(Cronbach's $\alpha$ )는 .87이었고, 본 연구에서는 .93으로 나타났 다. 하위요인별 신뢰도 계수(Cronbach's $\alpha$ )는 갈등적 수줍음 89 , 사회적 무관심.78, 사회적 회피 .89로 나타났다.

\section{연구절차}

유아의 사회적 위축, 실행기능, 행동억제기질과 어머니의 자
율성 지지 및 조사대상자의 일반적 특성에 대한 내용으로 설 문지를 구성하여 2021년 2월 9일부터 2021년 4월 5일까지 설 문조사를 통해 자료 수집을 하였다. 먼저 연구자가 보육기관 에 전화하여 원장 및 담당 보육교사에게 연구목적과 조사방법 을 설명한 후, 연구 참여에 대한 동의여부를 확인하였다. 연구 자는 연구 참여에 동의한 보육기관에 직접 방문하거나 우편을 이용하여 설문지를 배부하였으며, 어머니를 대상으로 한 설문 지는 유아를 통해 가정에 전달하였다. 담당 보육교사가 유아 의 사회적 위축을 평정한 교사용 설문지와 연구 참여에 동의 한 어머니에 한하여 어머니용 설문지를 함께 회수하였다. 담 당 보육교사가 유아의 사회적 위축을 평정한 교사용 설문지 와 어머니용 설문지를 함께 회수하였다. 설문 조사를 통해 총 297 부가 회수되었고, 이 중 누락되거나 불성실한 응답 자료 24 부를 제외한 273 부가 최종 분석 자료로 사용되었다.

\section{자료분석}

본 연구에서 수집된 자료는 SPSS 20.0 (IBM Co., Armonk, NY) 프로그램과 PROCESS Macro 3.5 프로그램을 사용하여 분석 하였다. 빈도분석, 기술통계를 실시하였으며, Cronbach's $\alpha$ 계 수를 산출하였다. 주요변인들 간의 상관관계를 알아보기 위하 여 Pearson의 상관분석을 실시하였다. 어머니의 자율성 지지와 유아의 사회적 위축간의 관계에서 실행기능과 행동억제기질 의 매개효과, 조절효과 및 조절된 매개효과를 검증하기 위해 SPSS PROCESS Macro의 Model 1번, 4번, 7번을 이용하였으며, 통계적 유의성을 확인하기 위해 부트스트래핑(bootstrapping) 을 실시하였다.

\section{Results}

\section{주요 변인들 간의 관계}

유아의 사회적 위축, 실행기능, 행동억제기질, 어머니의 자율 성 지지의 기술통계치와 Pearson 적률상관계수를 통해 상관관 계를 살펴보았으며, 결과는 Table 1과 같다.

Table 1에 의하면, 모든 변인이 왜도의 절대값 2.0 이내, 첨 도의 절대값이 4.0 이내로, 정규분포 조건을 충족하는 것으로 확인되었다(S. Hong, Malik, \& Lee, 2003).

다음으로 유아의 사회적 위축과 변인들 간의 상관관계를 구체적으로 살펴보면, 유아의 사회적 위축은 어머니의 자율 
Table 1

Means, Standard Deviations, and Correlations Among Variables

\begin{tabular}{lcccc}
\hline \multicolumn{1}{c}{ Variables } & 1 & 2 & 3 & 4 \\
\hline 1. Maternal autonomy support & - & & & \\
2. Executive function & $.29^{* *}$ & - & & \\
3. Behavioral inhibition & $-.24^{* *}$ & $-.42^{* *}$ & - & - \\
4. Social withdrawal & $-.23^{* *}$ & $-.56^{* *}$ & $.28^{* *}$ & 2.45 \\
\hline$M$ & 3.04 & 3.03 & 3.55 & .76 \\
$S D$ & .43 & .58 & .84 & .81 \\
skewness & -.28 & -.30 & -.58 & -.97 \\
kurtosis & 1.75 & -.97 & -.29 & \\
\hline
\end{tabular}

Note. $N=273$.

${ }^{* *} p<.01$.

Table 2

Mediating Effect of Executive Function on the Relationship Between Maternal Autonomy Support and Social Withdrawal in Young Children

\begin{tabular}{lclllllc}
\hline & & & & & \multicolumn{2}{c}{$95 \%$} \\
\cline { 5 - 8 } & Pathway & & $B$ & $S E$ & $t$ & LLCI & ULCI \\
\hline Maternal autonomy support & $\rightarrow$ & Executive function & .78 & .07 & $11.50^{* * *}$ & .65 & .92 \\
Maternal autonomy support & $\rightarrow$ & Social withdrawal & .30 & .11 & $-2.63^{* * *}$ & -.52 & -.08 \\
Executive function & $\rightarrow$ & Social withdrawal & -.54 & .08 & $-6.51^{* * *}$ & -.70 & -.38 \\
\hline
\end{tabular}

Note. $N=273$. LLCI = Lower limit confidence interval; ULCL $=$ Upper limit confidence interval.

${ }^{* * *} p<.001$.

성 지지 $(r=-.40, p<.01)$, 유아의 실행기능 $(r=-.51, p<.01)$ 과 부적 상관관계가 나타났다. 이는 유아의 사회적 위축의 높을 수록 어머니의 자율성 지지와 유아의 실행기능 수준이 낮아짐 을 의미한다. 유아의 사회적 위축은 행동억제기질 $(r=.21, p<$ .01)과 정적 상관이 나타났다. 이는 유아의 행동억제기질이 높 을수록 사회적 위축도 높아짐을 의미한다.

\section{어머니의 자율성 지지와 유아의 사회적 위축 간 의 관계에서 실행기능의 매개효과}

어머니의 자율성 지지와 유아의 사회적 위축 간의 관계에 서 유아의 실행기능의 매개효과 검증을 위해 Hayes (2018) 의 PROCESS Macro Model 4를 적용하였다. 부트스트랩핑을 5,000 회로 지정한 후 신뢰구간을 $95 \%$ 로 설정하여 분석한 결 과 Table 2, Figure 2와 같다.

Table 2에 의하면, 어머니의 자율성 지지는 실행기능에 정 적인 영향을 미쳤으며 $(B=.78, p<.001)$, 실행기능은 사회적 위축에 부적인 영향을 주어 $(B=-.54, p<.001)$ 실행기능은 어 머니의 자율성 지지와 유아의 사회적 위축 간의 관계를 매개 하였다. 또한 유아의 사회적 위축에 대한 어머니의 자율성 지

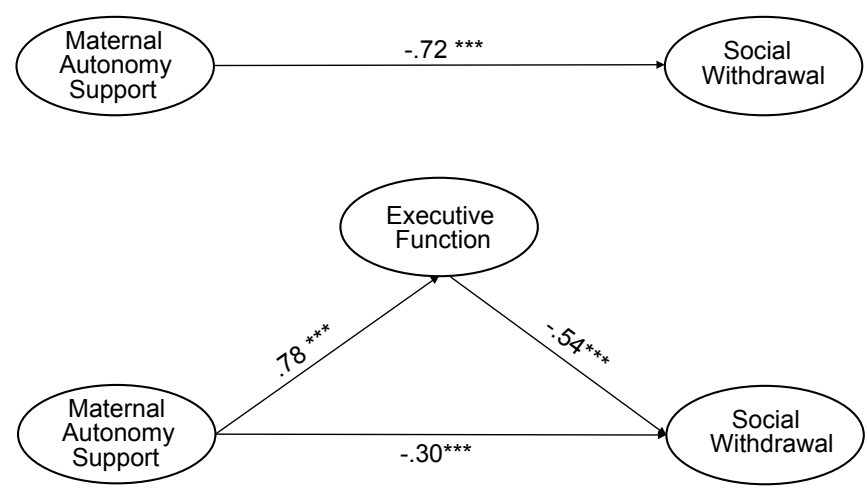

Figure 2. Mediating effect of executive function on the relation between maternal autonomy support and social withdrawal in young children.

${ }^{* * *} p<.001$.

지의 총 효과는 $B=-.72(p<.001)$ 이었으나 매개변수인 실행기 능이 투입되면서 사회적 위축에 대한 자율성 지지의 직접 효 과가 $B=-.30(p<.01)$ 으로 감소하여 실행기능이 매개하였음 을 알 수 있다.

어머니의 자율성 지지와 유아의 사회적 위축의 간접효과의 유의성 검증한 결과는 Table 3 과 같다.

Table 3에서 어머니의 자율성 지지와 유아의 사회적 위축의 
Table 3

Direct, Indirect, and Total Effects of Indirect Effects

\begin{tabular}{lcccc}
\hline & Effect & SE & LLCI & ULCI \\
\hline Total effect & -.72 & .10 & -.91 & -.52 \\
Direct effect & -.30 & .11 & -.52 & -.08 \\
Indirect effect & -.42 & .09 & -.61 & -.26 \\
\hline
\end{tabular}

Note. $N=273$. LLCI = Lower limit confidence interval; ULCL = Upper limit confidence interval.

Table 4

Moderating Effect of Behavioral Inhibition on the Relationship Between Maternal Autonomy Support and Executive Function in Young Children

\begin{tabular}{|c|c|c|c|c|c|}
\hline & \multirow[b]{2}{*}{$B$} & \multirow[b]{2}{*}{$S E$} & \multirow[b]{2}{*}{$t$} & \multicolumn{2}{|c|}{$95 \%$} \\
\hline & & & & LLCI & ULCI \\
\hline Maternal autonomy support (A) & .64 & .07 & $9.72^{* * *}$ & .51 & .78 \\
\hline \multirow[t]{2}{*}{$\mathrm{A} \times \mathrm{B}$} & .29 & .07 & $4.33^{* * *}$ & .16 & .42 \\
\hline & & $R^{2}$ & \multicolumn{3}{|c|}{$F$} \\
\hline
\end{tabular}

Note. $N=273$. LLCI = Lower limit confidence interval; ULCL $=$ Upper limit confidence interval.

${ }^{* * *} p<.001$.

Table 5

Significance of the Simple Slopes

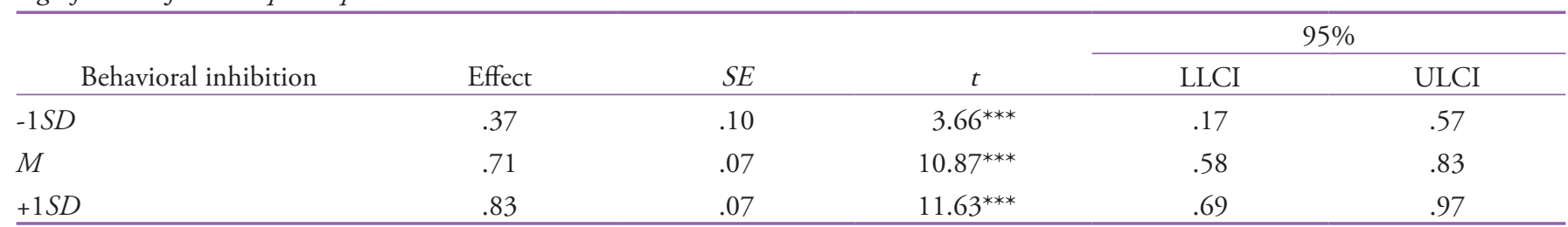

Note. $N=273$. LLCI = Lower limit confidence interval; ULCL = Upper limit confidence interval.

*** $p<.001$.

간접효과를 부트스트래핑을 활용하여 검증한 결과, 간접효과 크기는 -.42, 신뢰구간의 하한값은 -.61, 상한값은 -.26으로 나 타났다. 간접효과의 신뢰구간 사이에 0이 존재하지 않아 간접 효과가 유의한 것으로 검증되었다.

\section{어머니의 자율성 지지와 유아의 실행기능 간의 관계에서 행동억제기질의 조절효과}

어머니의 자율성 지지와 유아의 실행기능 사이에서 유아의 행 동억제기질의 조절효과를 검증하기 위하여 Hayes (2018)가 제 안한 PROCESS Macro Model 1을 이용하였다. 부트스트랩핑 5,000 회로 지정한 후 신뢰구간은 95\%로 설정하고, 다중공선 성 문제를 최소화하기 위하여 독립변인과 조절변인을 평균중 심화 하여 분석을 실시한 결과는 Table 4 와 같다.

Table 4에 의하면, 어머니의 자율성 지지는 유아의 실행기
능에 정적으로 유의한 영향을 미쳤고 $(B=.64, p<.001)$, 유아 의 행동억제기질은 실행기능에 부적으로 유의한 영향을 미쳤 다 $(B=-.21, p<.001)$.

어머니의 자율성 지지와 유아의 행동억제기질의 상호작용 항은 실행기능에 정적으로 유의한 영향을 미쳐 조절효과가 있 었다 $(B=.29, p<.001)$. 또한 상호작용에 따른 $R^{2}$ 의 변화량은 $\triangle R^{2}=.04(p<.001)$ 이었고, 통계적으로 유의하여 어머니의 자율성 지지와 유아의 실행기능과의 관계에서 행동억제기질 의 조절효과가 검증되었다.

어머니의 자율성 지지와 유아의 실행기능 간의 관계에서 행동억제기질의 조절효과를 확인하고, 단순회귀선의 유의성 을 검증한 결과는 Table 5 와 같다.

Table 5에 의하면, 어머니의 자율성 지지가 유아의 실행기 능에 미치는 영향에서 행동억제기질이 낮은 집단 $(B=.37, p<$ $.001)$, 중간 집단 $(B=.71, p<.001)$, 높은 집단 $(B=.83, p<.001)$ 


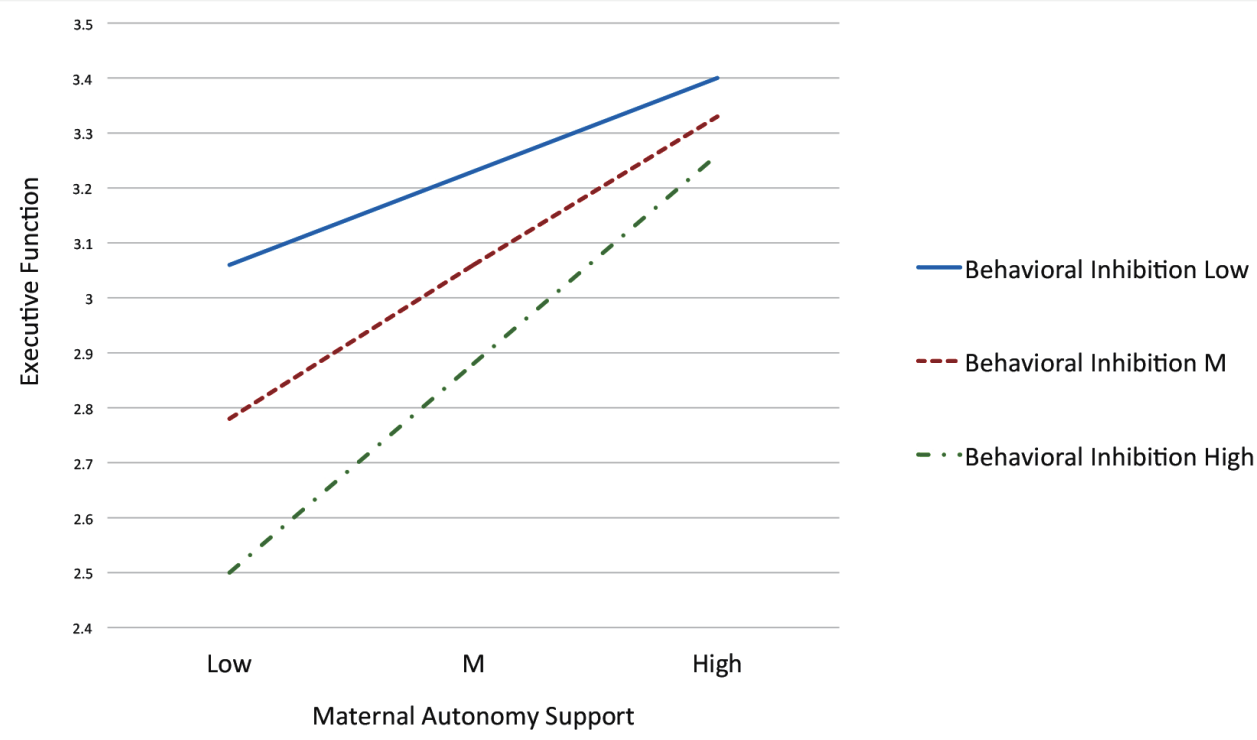

Figure 3. Moderating effect of behavioral inhibition on the relation between maternal autonomy support and executive function.

Table 6

Moderated Mediation Effect of Behavioral Inhibition on the Relationship Between Maternal Autonomy Support, Executive Function and Social Withdrawal in Young Children

\begin{tabular}{|c|c|c|c|c|c|}
\hline & \multicolumn{5}{|c|}{ DV: Executive function } \\
\hline & \multirow[b]{2}{*}{$B$} & \multirow[b]{2}{*}{$S E$} & \multirow[b]{2}{*}{$t$} & \multicolumn{2}{|c|}{$95 \% \mathrm{CI}$} \\
\hline & & & & LLCI & ULCI \\
\hline Constant & 3.06 & .08 & $111.21^{* * *}$ & 3.00 & 3.10 \\
\hline Maternal autonomy support (A) & .64 & .07 & $9.72^{* * *}$ & .51 & .78 \\
\hline Behavioral inhibition (B) & -.21 & .03 & $-6.11^{* * *}$ & -.28 & -.14 \\
\hline \multirow[t]{4}{*}{$\mathrm{A} \times \mathrm{B}$} & .29 & .07 & $4.33^{* * *}$ & .16 & .42 \\
\hline & \multicolumn{5}{|c|}{ DV: Social withdrawal } \\
\hline & & & & & \\
\hline & $B$ & $S E$ & $t$ & LLCI & ULCI \\
\hline Constant & 4.08 & .25 & $12.06^{* * *}$ & 3.58 & 4.58 \\
\hline Maternal autonomy support & -.30 & .11 & $-2.63^{* *}$ & -.52 & -.08 \\
\hline Executive function & -.54 & .08 & $-6.51^{* * *}$ & -.70 & -.38 \\
\hline
\end{tabular}

Note. $N=273$. LLCI $=$ Lower limit confidence interval; ULCL $=$ Upper limit confidence interval.

${ }^{* *} p<.01 .{ }^{* * *} p<.001$.

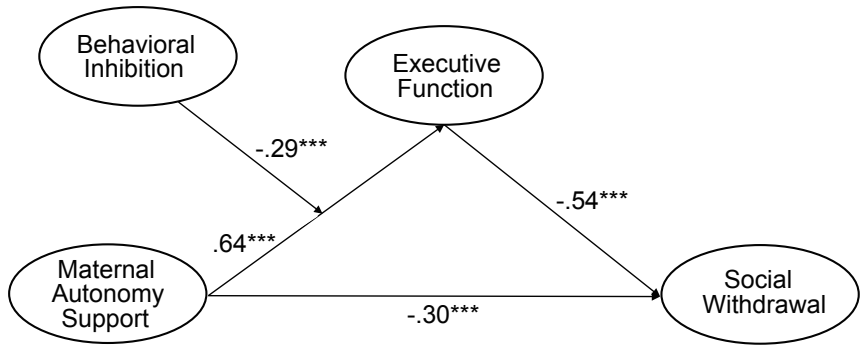

Figure 4. Statistical diagram. ${ }^{* * *} p<.001$.
에서 모두 유의미하였다. 이는 행동억제기질 수준이 높아질수 록 어머니의 자율성 지지가 유아의 실행기능에 미치는 영향이 더 증가하는 것을 의미한다.

다음으로 행동억제기질의 상호작용효과를 구체적으로 살 펴보기 위해 조절효과를 시각화한 결과는 Figure 3 과 같다.

Figure 3에 의하면, 어머니의 자율성 지지와 유아의 실행기 능의 관계에서 행동억제기질 수준이 낮은 집단 $(B=.37, p<$ $.001)$, 중간 집단 $(B=.71, p<.001)$, 높은 집단 $(B=.83, p<.001)$ 에서 모두 정적으로 유의미하였다. 구체적으로 어머니의 자율 
Table 7

Index of moderated mediation of Behavioral Inhibition on the Relationship Between Maternal Autonomy Support, Executive Function and Social Withdrawal in Young Children

\begin{tabular}{cccc}
\hline Index of moderated mediation & $S E$ & Boot LLCI & Boot ULCI \\
\hline-.16 & .05 & -.26 & -.08 \\
\hline
\end{tabular}

Note. $\mathrm{N}=273$. LLCI = Lower limit confidence interval; ULCL = Upper limit confidence interval.

Table 8

Significance of the Moderated Mediating Effect

\begin{tabular}{lcccc}
\hline \multicolumn{1}{c}{ Behavioral inhibition } & Effect & $S E$ & LLCI & ULCI \\
\hline$-1 S D$ & -.20 & .08 & -.37 & -.07 \\
$M$ & -.38 & .08 & -.54 & -.25 \\
$+1 S D$ & -.45 & .09 & -.63 & -.30 \\
\hline
\end{tabular}

Note. $N=273$. LLCI = Lower limit confidence interval; ULCL = Upper limit confidence interval.

성 지지와 실행기능 간의 관계에서 행동억제기질이 높은 집단 의 경우, 낮은 집단에 비해 기울기가 더욱 높아진다. 즉, 행동 억제기질 수준이 높은 경우, 어머니가 자율성 지지를 많이 해 줄수록 실행기능이 더 향상됨을 알 수 있다.

\section{어머니의 자율성 지지, 유아의 실행기능, 사회적 위축 간의 관계에서 행동억제기질의 조절된 매개 효과}

어머니의 자율성 지지가 유아의 실행기능을 거쳐 사회적 위축 에 이르는 경로에서 행동억제기질의 조절된 매개효과를 검증 하기 위해 PROCESS Macro Model 7을 이용하였고, 부트스트 랩핑 5,000회를 지정하고 $95 \%$ 의 신뢰구간을 설정하였다. 독 립변인, 조절변인, 매개변인을 평균중심화 하여 분석을 실시 하였다.

Table 6에 의하면, 어머니의 자율성 지지는 실행기능에 정 적인 영향을 미쳤고 $(B=.64, p<.001)$, 실행기능은 사회적 위 축에 부적인 영향을 미쳤으며 $(B=-.54, p<.001)$, 각각 통계적 으로 유의하여 매개효과가 있었다. 그리고 어머니의 자율성 지지는 사회적 위축에 부적인 영향을 미쳤으며 $(B=-.30, p<$ $.01)$, 어머니의 자율성 지지와 행동억제기질의 상호작용항은 실행기능에 정적인 영향을 미쳐 $(B=.29, p<.001)$ 조절된 매개 효과가 있었다. 즉, 어머니의 자율성 지지와 사회적 위축 간의 관계에서 실행기능의 매개효과가 행동억제기질 수준에 따라 달라진다.

조절된 매개효과의 유의성을 검증하기 위해 부트스트래핑 을 사용하여 행동억제기질의 조절된 매개지수로 조건부 간 접효과를 분석한 결과, 조절된 매개지수는 $B=-.16$ 로 나타났
고, $95 \%$ 의 신뢰구간에서 하한값이 -.26, 상한값이 -.08로 0이 포함되지 않아 조절된 매개효과가 유의한 것으로 나타났다 (Table 7). 이에 행동억제기질의 구체적인 유의성을 검증하기 위해 조건부 간접효과를 확인한 결과는 Table 8과 같다.

Table 8에 의하면, 행동억제기질이 낮은 집단, 중간 집단, 높 은 집단 모두에서 하한값과 상한값 사이에 0이 포함되지 않아 조절된 매개효과가 유의함을 알 수 있다. 행동억제기질 수준이 높을수록 변화량이 증가하였는데, 이는 행동억제기질 수준이 높아질수록 어머니의 자율성 지지와 유아의 사회적 위축의 관 계에서 실행기능의 매개효과가 높아지는 것을 의미한다. 따라 서 유아의 행동억제기질은 어머니의 자율성 지지가 실행기능을 거쳐 유아의 사회적 위축으로 가는 경로를 조절 매개하였다.

\section{Discussion}

본 연구의 목적은 만 3,4 세 유아와 그들의 어머니를 대상으로 어머니의 자율성 지지와 유아의 사회적 위축 간의 관계에서 실행기능의 매개효과를 확인하고, 이러한 매개 관계에서 유아 의 행동억제기질의 조절적 역할을 확인하는 것이다. 이를 통 해 유아가 상호작용하는 환경적 맥락과 더불어 유아의 개인 내적인 요인을 함께 고려함으로써 사회적 위축의 개인차를 설 명하는 심리적 과정에 대한 이해를 확장하고, 유아기 사회적 위축의 예방 및 중재를 위한 효과적인 개입방법의 근거를 제 공하고자 하였다. 본 연구의 결과를 요약하고 논의하면 다음 과 같다.

첫째, 유아의 실행기능은 어머니의 자율성 지지와 유아의 사회적 위축의 관계를 부분 매개하는 것으로 나타났다. 즉, 어 
머니의 자율성 지지는 유아의 사회적 위축을 감소시키거나 혹 은 어머니의 자율성 지지가 유아의 실행기능을 향상시켜 사 회적 위축을 감소시켰다. 이는 어머니로부터 자율성을 지지해 주는 양육행동을 경험한 유아가 사회적으로 덜 위축된다는 선 행연구(Park, 2013)를 지지하는 결과이며, 어머니가 유아의 관 점을 수용하고 애정을 표현할수록 실행기능이 높아져 사회적 위축이 감소하였다는 연구(S.-R. Kim, 2020)와 유사한 맥락이 다. 또한 어머니가 유아의 자율성을 지지하는 양육행동을 보 일수록 실행기능이 높았고, 그 결과 유아는 또래관계에서 더 유능하며 친사회적 행동을 더 많이 보인다는 연구결과(Moon \& Shin, 2017)와 유사하다.

어머니가 유아의 자율성을 지지해 줄 경우, 유아는 주도적 으로 문제를 해결하는 경험을 하게 된다(Joussemet et al., 2005). 이를 통해 유아는 자신의 정서, 사고, 행동을 조절하는 실행기 능이 향상되어 또래와의 관계에서 위축된 행동이 감소하는 것 으로 생각된다. 또한 어머니가 유아의 독립심을 격려할수록 유 아는 적극적으로 또래에게 접근하고, 여러 가지 사회적 기술을 연습함으로써 상황에 적합한 상호작용 방법을 습득한다(Park, 2013). 즉, 어머니가 유아의 자율성을 촉진할 때, 타인과의 관계 에서 위축되지 않고 긍정적인 사회적 관계를 맺는 것과 더불어 유아의 실행기능이 증진되어 충동적인 자신의 사고와 행동을 조절하여 사회적 위축을 감소시키는 것으로 해석할 수 있다.

둘째, 행동억제기질 수준이 높을수록 어머니의 자율성 지 지가 실행기능에 미치는 긍정적 영향이 더 커졌다. 즉, 유아의 행동억제기질 수준이 높더라도 어머니가 유아의 자율성을 지 지해 주면 실행기능이 더 향상될 수 있음을 의미한다. 이는 자 신의 사고와 행동을 조절하지 못하는 기질적 특성을 가진 유 아에게 어머니가 민감하고 자율적인 양육을 제공하였을 때, 인지능력이 더욱 유의하게 증가함을 보고한 M.-K. Kim (2011) 의 연구와 유사한 맥락에서 해석할 수 있다. 행동억제기질의 경우 실행기능에 대한 조절효과를 살펴본 연구가 존재하지 않아 본 연구의 결과와 직접 비교하기는 어렵지만 낮선 환경 을 두려워하는 유아의 경우, 부모가 유아를 수용하고 관여하 지 않는 양육을 제공하였을 때, 실행기능의 한 영역인 억제통 제가 향상되었다는 연구(Rochette \& Bernier, 2016; Suor et al., 2019)와 유사하다.

행동억제기질 수준이 높은 유아의 경우, 어머니는 유아가 독 립적으로 문제를 해결하고 의사결정을 할 수 있도록 장려함으 로써 유아는 새로운 환경에서 주도적으로 선택하는 기회를 많 이 경험할 수 있다(Joussemet et al., 2005). 이는 상황에 대한 예측 가능성을 높여 유아가 자신의 정서와 행동을 조절하는 인지적
능력을 향상시키는 것으로 생각된다(Rochette \& Bernier, 2016). 본 연구에서는 어머니의 애정적이고 긍정적인 양육행동의 중요 성을 검증한 선행연구들과 달리 다양한 양육행동 중에서도 특 히 행동억제기질 수준이 높은 유아의 실행기능을 증진시킬 수 있는 자율성 지지가 중요한 요소임을 알 수 있었다.

셋째, 어머니의 자율성 지지가 유아의 실행기능을 매개하 여 유아의 사회적 위축에 미치는 관계에서 유아의 행동억제기 질의 조절된 매개효과는 유의하게 나타났다. 구체적으로 행동 억제기질 수준이 높을수록, 어머니의 자율성 지지가 유아의 사회적 위축에 미치는 영향에서 실행기능의 매개효과가 높은 것으로 나타났다.

행동억제기질 수준이 높은 유아의 경우, 낮선 상황에 대한 두려움에 주의가 편향되어 유연하게 사고를 전환하는 능력이 감소한다(Gramiszlo, Geronimi, Arellano, \& Woodruff-Borden, 2018). 이는 유아가 긍정적인 사고로의 전환이 어려워 또래와 의 관계에서 위축된 행동을 보이는 것으로 생각된다. 이러한 결과는 환경적인 요인에 비해 실행기능이 사회적 위축을 예 측하는 중요한 요인이라고 밝힌 Selcuk, Yavuz, Etel, Harma와 Ruffman (2017)의 연구와 비슷한 맥락이다. 그러나 어머니가 스스로 하려는 유아의 의지를 지지할 때, 유아가 주도적으로 대처할 수 있는 능력을 키울 수 있으며, 자신의 행동을 조절할 수 있게 된다(Deci \& Ryan, 1985). 또한 사회적 상황에서 자신 의 정서를 정확하게 인식하고 조절하여 위축을 덜 보이는 것 으로 해석할 수 있다. 즉, 행동억제기질이 높은 유아는 어머니 가 자율성을 지지해 주면 실행기능이 증진되어 사회적 위축이 감소되는 것으로 생각된다. 따라서 환경적 변화와 더불어 개 인의 인지적 특성인 실행기능의 변화는 유아의 사회적 위축을 예측하는 중요한 요소임을 시사한다.

이러한 결과는 뇌 과학적 관점에서 설명될 수 있다. Schmidt와 Miskovic (2013)의 연구에 따르면, 행동억제기질 수준이 높은 유아의 경우 어떤 양육환경이 제공되는가에 따 라 다른 발달 결과를 야기한다. 유아에게 긍정적인 양육행동 을 제공하면 좌측 전두엽이 활성화되는 반면, 부정적이고 스 트레스가 많은 양육환경을 제공하면 우측 전두엽이 활성화된 다(McLaughlin, Fox, Zeanah, \& Nelson, 2011). 이때, 행동억제 기질 수준이 높은 유아에게 긍정적인 양육환경이 제공되는 경 우, 좌측 전두엽이 활성화되어 자기조절능력과 정서조절능력 이 증진되고 이는 또래와의 성공적인 관계 형성에 영향을 미 쳤을 것이다(Coan \& Allen, 2004; Schmidt \& Miskovic, 2013). 이러한 메커니즘은 행동억제기질에 의해 차별적 민감성 가설 (Belsky \& Pluess, 2009)이 지지될 수 있음을 제안한 Schmidt와 
Miskovic (2013)의 연구와 맥을 같이 한다. 또한 친숙하지 않은 상황에서 불안을 느끼는 기질의 수준이 높은 아동의 경우, 어 머니와 긍정적인 관계를 맺을수록 더 나은 발달결과를 보였다 는 연구(J. Han, Lee, \& Kim, 2020)와도 유사한 맥락이다. 이처 럼 까다롭고 민감한 기질의 유아는 자신의 정서나 사고를 조 절하는 데 어려움을 겪지만, 이러한 유아일수록 어머니가 유 아의 자율성을 지지하는 양육태도를 발휘하면, 순한 기질의 유아에 비해 양육의 영향을 많이 받는 것으로 볼 수 있다. 이는 선행연구에서 차별적 민감성 모델 검증을 위해 포괄적인 기질 적 특성을 다루었던 것과 달리 행동억제기질이라는 구체적인 기질적 특성도 환경에 민감하게 작용할 수 있음을 보여준다. 따라서 행동억제기질 수준이 높은 유아의 사회적 위축을 감소 시키기 위해서는 유아가 주도적으로 결정을 할 수 있도록 지 지해주는 양육행동을 제공하여 자신의 정서, 사고를 조절하고 타인의 생각과 행동을 예측하는 실행기능을 증진시키는 것이 중요함을 시사한다.

종합하면, 본 연구의 결과는 유아가 낯선 환경을 두려워하 더라도 어머니가 유아의 행동을 지지해 주면 유아가 독립적으 로 환경을 탐색하도록 도울 수 있고, 이는 새로운 상황에서 문 제해결능력이 상승되어 사회적 위축이 감소할 수 있음을 보여 준다. 즉, 행동억제기질 수준이 높은 아동이라 하더라도 어머 니의 자율적이고 지지적인 양육환경은 충동적 행동을 조절하 고 주의를 전환하는 실행기능을 발달시켜 사회적 위축을 감소 시키는 역할로 작용할 수 있음을 시사한다. 이는 어머니의 양 육행동은 유아의 사회적 위축을 감소시키는데 중요한 역할로 작용하며, 어머니의 자율성 지지와 더불어 유아의 실행기능을 함께 고려해야 함을 의미한다.

마지막으로 본 연구의 제한점과 후속 연구를 위한 제언은 다음과 같다.

첫째, 본 연구에서는 실행기능의 부분매개효과가 나타났기 에 어머니의 자율성 지지가 유아의 사회적 위축에 이르는 대안 적 경로들이 있을 것으로 예상된다. 따라서 후속 연구에서 사회 적 위축과 관련한 다양한 매개 변인들을 확장시킬 필요가 있다.

둘째, 본 연구에서는 어머니의 자율성 지지와 유아의 사회 적 위축 간의 관계에서 행동억제기질의 조절효과를 가정하지 않았다. 그러나 행동억제기질 외에 까다로운 기질을 고려하였 을 때, 어머니의 긍정적인 양육행동과 유아의 내재화 문제행 동 간의 조절효과가 나타난 선행연구(Belsky \& Pluess, 2009)와 는 차이가 있다. 따라서 두 변인 간의 관계에서 행동억제기질 의 조절적 역할 가능성이 있어 추후 연구에서는 이에 대하여 검증할 필요가 있다.
셋째, 본 연구의 예비분석 결과 유아의 연령에 따른 실행기 능의 차이가 나타나지 않았다. 하지만 실행기능 간의 연령차 가 존재한다는 선행연구(Kang \& Kim, 2018; Y.-M. Kim, 2018) 와는 상반된 결과이다. 이는 모의 보고로 이루어진 BRIEF 척 도의 경우, 모가 유아의 실행기능을 주관적 판단하여 실제 능 력보다 더 높이 평가하였을 가능성이 있다. 따라서 후속연구 에서는 실행기능에 따른 연령차를 고려하고 어머니 평정 외에 도 과제와 같은 측정 방법을 함께 사용할 필요가 있다.

이러한 제한점에도 불구하고 본 연구는 선행연구들이 어 머니의 자율성 지지와 사회적 위축의 관계를 검증하거나 매 개효과와 조절효과를 검증한 것과 달리, 두 변인 간의 관계에 서 실행기능의 매개효과와 행동억제기질의 조절된 매개효과 를 검증함으로써 통합적인 관점에서 하나의 모형으로 밝혔다 는데 의의가 있다. 또한 유아의 발달을 이해하고 분석하기 위 해서는 각 변인들을 통합적으로 포괄하여 검증하는 것이 중 요하다. 이에 본 연구는 환경적 변인과 유아의 기질간의 상호 작용과 더불어 양육의 결과로 나타나는 유아의 인지적 특성을 고려하여 통합된 모형으로 검증함으로써 사회적 위축 예방을 위한 이해의 폭을 넓혔다는 점에서 의의가 있다. 또한 까다로 운 기질과 같은 비교적 포괄적인 기질적 특성에만 초점이 맞 춰졌던 차별적 민감성 가설을 행동억제기질이라는 구체적인 기질적 특성을 통해 검증함으로써 선행연구의 결과(Belsky \& Pluess, 2009; Bradley \& Corwyn, 2008)를 확장하였다는데 의의 가 있다. 본 연구의 결과를 토대로 유아의 사회적 위축을 예방 하기 위한 어머니의 자율성 지지 및 유아의 실행기능의 중요 성을 규명하고, 유아의 기질과 양육행동을 바탕으로 사회적 위축의 개인차를 설명할 수 있을 것이다. 이를 통해 유아의 사 회적 위축을 조기에 중재할 수 있는 부모교육 프로그램 개발 및 조기 중재 프로그램의 자료로 활용될 수 있을 것이다.

\section{Notes}

This article is a part of the first author's master's thesis submitted in 2021, and was presented as a poster at the 2021 Annual Spring Conference of the Korean Association of Child Studies.

\section{Conflict of Interest}

No potential conflict of interest relevant to this article was reported. 


\section{References}

\section{In English}

Belsky, J. (1997). Theory testing, effect-size evaluation, and differential susceptibility to rearing influence: The case of mothering and attachment. Child Development, 68(4), 598-600. doi:10.1111/j.1467-8624.1997.tb04221.x

Belsky, J., \& Pluess, M. (2009). Beyond diathesis stress: Differential susceptibility to environmental influences. Psychological Bulletin, 135(6), 885-908. doi:10.1037/a0017376

Bernier, A., Carlson, S. M., Deschênes, M., \& Matte-Gagné, C. (2012). Social factors in the development of early executive functioning: A closer look at the caregiving environment. Developmental Science, 15(1), 12-24. doi:10.1111/j.14677687.2011.01093.x

Bradley, R. H., \& Corwyn, R. F. (2008). Infant temperament, parenting, and externalizing behavior in first grade: A test of the differential susceptibility hypothesis. Journal of Child Psychology and Psychiatry, 49(2), 124-131. doi:10.1111/ j.1469-7610.2007.01829.x

Buss, K. A., \& Kiel, E. J. (2013). Temperamental risk factors for pediatric anxiety disorders. In R. A. Vasa \& A. K. Roy (Eds.), Pediatric anxiety disorders: A clinical guide (pp. 4768). Totowa, NJ: Human Press.

Chevalier, N., \& Clark, C. A. C. (2017). Executive function in early and middle childhood. In S. A. Wiebe \& J. Karbach (Eds.), Executive function: Development across the life span (pp. 11-28). London: Routledge.

Coan, J. A., \& Allen, J. J. (2004). Frontal EEG asymmetry as a moderator and mediator of emotion. Biological psychology, 67(1-2), 7-50. doi:10.1016/j.biopsycho.2004.03.002

Coplan, R. J., \& Ooi, L. (2014). The causes and consequences of "playing alone" in childhood. In R. J. Coplan \& J. C. Bowker (Eds.), The handbook of solitude: Psychological perspectives on social isolation, social withdrawal, and being alone (pp. 111128). Hoboken, NJ: John Wiley \& Sons.

Coplan, R. J., Ooi, L. L., Xiao, B., \& Rose-Krasnor, L. (2018). Assessment and implications of social withdrawal in early childhood: A first look at social avoidance. Social Development, 27(1), 125-139. doi:10.1111/sode.12258

Deci, E. L., \& Ryan, R. M. (1985). The general causality orientations scale: Self-determination in personality. Journal of Research in Personality, 19(2), 109-134. doi:10.1016/ 0092-6566(85)90023-6

Feola, B., Dougherty, L. R., Riggins, T., \& Bolger, D. J. (2020). Prefrontal cortical thickness mediates the association between cortisol reactivity and executive function in childhood. Neuropsychologia, 148(107636), 1-9. doi:10.1016/ j.neuropsychologia.2020.107636

Fox, N. A., Henderson, H. A., Marshall, P. J., Nichols, K. E., \& Ghera, M. M. (2005). Behavioral inhibition: Linking biology and behavior within a developmental framework. Annual Review of Psychology, 56, 235-262. doi:10.1146/ annurev.psych.55.090902.141532

Gazelle, H., \& Ladd, G. W. (2003). Anxious solitude and peer exclusion: A diathesis-stress model of internalizing trajectories in childhood. Child Development, 74(1), 257278. doi:10.1111/1467-8624.00534

Gioia, G. A., Isquith, P. K., Guy, S. C., \& Kenworthy, L. (2000). Test review behavior rating inventory of executive function. Child Neuropsychology, 6(3), 235-238. doi:10.1076/ chin.6.3. 235.3152

Grolnick, W. S., Gurland, S. T., DeCourcey, W., \& Jacob, K. (2002). Antecedents and consequences of mothers' autonomy support: An experimental investigation. Developmental Psychology, 38(1), 143-155. doi:10.1037/0012-1649.38.1.143

Gramszlo, C., Geronimi, E. M., Arellano, B., \& WoodruffBorden, J. (2018). Testing a cognitive pathway between temperament and childhood anxiety. Journal of Child and Family Studies, 27, 580-590. doi:10.1007/s10826-017-0914-2

Hayes, A. F. (2018). Partial, conditional, and moderated moderated mediation: Quantification, inference, and interpretation. Communication Monographs, 85(1), 4-40. doi:10.1080/036 37751.2017 .1352100

Hong, S., Malik, M. L., \& Lee, M.-K. (2003). Testing configural, metric, scalar, and latent mean invariance across genders in sociotropy and autonomy using a non-Western sample. Educational and Psychological Measurement, 63(4), 636-654. doi:10.1177/0013164403251332

Joussemet, M., Koestner, R., Lekes, N., \& Landry, R. (2005). A longitudinal study of the relationship of maternal autonomy support to children's adjustment and achievement in school. Journal of Personality, 73(5), 1215-1236. doi:10.1111/j.14676494.2005.00347.x

Kiel, E. J., \& Buss, K. A. (2011). Prospective relations among fearful temperament, protective parenting, and social withdrawal: The role of maternal accuracy in a moderated mediation framework. Journal of Abnormal Child Psychology, 39(7), 953-966. doi:10.1007/s10802-011-9516-4

Kiel, E. J., \& Buss, K. A. (2014). Dysregulated fear in toddlerhood predicts kindergarten social withdrawal through protective parenting. Infant and Child Development, 23(3), 304-313. doi: $10.1002 /$ icd. 1855

Liew, J. (2012). Effortful control, executive functions, and education: Bringing self-regulatory and social-emotional competencies to the table. Child Development Perspectives, 6(2), 105-111. doi:10.1111/j.1750-8606.2011.00196.x

Pérez-Edgar, K., Reeb-Sutherland, B. C., McDermott, J. M., 
White, L. K., Henderson, H. A., Degnan, K. A.,...Fox, N. A. (2011). Attention biases to threat link behavioral inhibition to social withdrawal over time in very young children. Journal of Abnormal Child Psychology, 39, 885-895. doi:10.1007/ s10802-011-9495-5

McLaughlin, K. A., Fox, N. A., Zeanah, C. H., \& Nelson, C. A. (2011). Adverse rearing environments and neural development in children: The develop ment of frontal electroencephalogram asymmetry. Biological Psychiatry, 70(11), 1008-1015. doi:10.1016/j.biopsych.2011.08.006

Rochette, É., \& Bernier, A. (2016). Parenting and preschoolers' executive functioning: A case of differential susceptibility? International Journal of Behavioral Development, 40(2), 151161. doi:10.1177/0165025414557370

Rubin, K., Both, L., \& Wilkinson, M. (1990). The Waterloo longitudinal project: Correlates and consequences of social withdrawal in childhood. Infanciay Aprendizaje, 49, 73-90.

Rubin, K. H., Coplan, R. J., \& Bowker, J. C. (2009). Social withdrawal in childhood. Annual Review of Psychology, 60, 141-171. doi:10.1146/annurev.psych.60.110707.163642

Schmidt, L. A., \& Miskovic, V. (2013). Shyness and the electrical activity of the brain: On the interplay between theory and method. In R. J. Coplan \& J. C. Bowker (Eds.), The handbook of solitude: Psychological perspectives on social isolation, social withdrawal, and being alone (pp. 51-70). Hoboken, NJ: John Wiley \& Sons.

Selcuk, B., Yavuz, H. M., Etel, E., Harma, M., \& Ruffman, T. (2017). Executive function and theory of mind as predictors of socially withdrawn behavior in institutionalized children. Social Development, 27(1), 109-124. doi:10.1111/sode.12252

Suor, J. H., Sturge-Apple, M. L., Davies, P. T., \& Jones-Gordils, H. R. (2019). The interplay between parenting and temperament in associations with children's executive function. Journal of Family Psychology, 33(7), 841-850. doi:10.1037/fam0000558

Thai, N., Taber-Thomas, B. C., \& Pérez-Edgar, K. E. (2016). Neural correlates of attention biases, behavioral inhibition, and social anxiety in children: An ERP study. Developmental Cognitive Neuroscience, 19, 200-210. doi:10.1016/j.dcn. 2016.03.008

Toren, P., Sadeh, M., Wolmer, L., Eldar, S., Koren, S., Weizman, R., \& Laor, N. (2000). Neurocognitive correlates of anxiety disorders in children: A preliminary report. Journal of Anxiety Disorders, 14(3), 239-247. doi:10.1016/S08876185(99)00036-5

Welsh, M. C., Pennington, B. F., \& Groisser, D. B. (1991). A normative-developmental study of executive function: A window on prefrontal function in children. Developmental Neuropsychology, 7(2), 131-149. doi:10.1080/87565649109 540483

Younger, A. J., \& Daniels, T. M. (1992). Children's reasons for nominating their peers as withdrawn: Passive withdrawal versus active isolation. Developmental Psychology, 28(5), 955-960. doi:10.1037/0012-1649.28.5.955

Zarra-Nezhad, M., Kiuru, N., Aunola, K., Zarra-Nezhad, M., Ahonen, T., Poikkeus, A.-M.,...Nurmi, J.-E. (2014). Social withdrawal in children moderates the association between parenting styles and the children's own socioemotional development. Journal of Child Psychology and Psychiatry, 55(11), 1260-1269. doi:10.1111/jcpp.12251

\section{In Korean}

Cha, M. (2018). Relationships among preschoolers' executive function, preschool adjustment, school readiness, temperament, and maternal parenting (Master's thesis). Retrieved from http:// www.riss.kr/link?id=T14712237

Han, J. A. (2016). Effects of preschool children's temperament, emotional regulation and maternal coping behavior on gender-specific children's withdrawal behavior. Korean Journal of Human Ecology, 25(3), 281-293. doi:10.5934/ kjhe.2016.25.3.281

Han, J., Lee, D., \& Kim, J. (2020). Moderating effect of shyness on the association between maternal communication and wellbeing among upper elementary school students based on differential susceptibility model. Asian Journal of Education, 21(4), 953-974. doi:10.15753/aje.2020.12.21.4.953

Hong, H. G. (2015). The effect of maternal parenting behavior on children's problem behavior: The mediating effects of father's participation (Master's thesis). Retrieved from http://www. riss.kr/link?id=T13849666

Jo, W. R., \& Shin, N. (2017). Effects of young children's shyness on social withdrawal of young children: Focusing on moderating effects of teacher-child relationships. Family and Environment Research, 55(4), 419-431. doi:10.6115/ fer.2017.030

Jung, S., \& Seo, D. G. (2016). Assessing mediated moderation and moderated mediation: Guidelines and empirical illustration. Korean Journal of Psychology: General, 35(1), 257-282. doi:10.22257/kjp.2016.03.35.1.257

Kang, D. Y., \& Kim, W. (2018). The effect of mothers emotional socialization behaviors and young children's executive function on young childrens emotional regulation ability. The Journal of Korea Open Association for Early Childhood Education, 23(1), 259-279. doi:10.20437/KOAECE23-1-10

Kim, M.-K. (2011). The effects of the maternal parenting behaviors on toddler's development and behaviors: The moderating role of the toddler's gender and temperament (Doctoral dissertation). Retrieved from http://www.riss.kr/link?id=T12322315

Kim, S.-R. (2020). The effects of maternal parenting behavior 
on preschoolers' social behavior: The mediating effect of preschoolers' executive function (Master's thesis). Retrieved from http://www.riss.kr/link?id=T15632193

Kim, W., Kim, J., Lee, I., \& Nam, Y. (2014). A structural relationship study of young children's negative peer interaction behaviors and related variables. Journal of Early Childhood Education, 34(2), 29-48.

Kim, Y.-M. (2018). The development of children's hot and cool executive function and relationship between language ability. The Journal of Korea Early Childhood Education, 25(3), 131-157. doi:10.22155/JFECE.25.3.131.157

Ko, B. (2019). Relationship between young children's social withdrawal and preschool adjustment: The moderating effects of teacher-child relationship and maternal management strategies for children's peer relationship (Master's thesis). Retrieved from http://www.riss.kr/link?id=T15073501

Lee, H. R. (2020). The effects of preschoolers' behavioral inhibition on the anxiety: The mediation effects of maternal overprotective parenting and autonomy support (Master's thesis). Retrieved from http://www.riss.kr/link?id=T15632237

Moon, J., \& Shin, N. (2017). The effects of maternal autonomy support on preschoolers' emotional and social competence: The mediating effect of preschoolers' executive function. Korean Journal of Child Studies, 38(6), 17-33. doi:10.5723/ kjcs.2017.38.6.17

Noh, B.-H., Park, S.-Y., \& Chee, Y. K. (2011). The relationship between socioeconomic status, maternal involvement in learning, parenting behavior and children's self-determination motivation. Korean Journal of Child Studies, 32(4), 83-97.

Park, B.-K. (2013). Relations among toddlers' temperament, maternal parenting, and social withdrawal and aggression. Journal of Korean Home Management Association, 31(6), $67-$ 81. doi:10.7466/JKHMA.2013.31.6.67

Seo, J., \& Park, H. (2011). The effects of emotional intelligenceon executive function: A comparison between normal children and attention deficit children. Journal of Cognitive Enhancement and Intervention, 2(1), 99-127.

Seo, Y. H. (2013). The effects of temperament and positive parenting attitude on preschooler's internalizing problems (Master's thesis). Retrieved from http://www.riss.kr/link?id=T13156892

\section{ORCID}

Su Lim Kang https://orcid.org/0000-0002-5318-9084

Sunhee Kim http://orcid.org/0000-0002-0801-6918

Received June 30, 2021

Revision received August 27, 2021

Accepted September 13, 2021 